\title{
Enhanced recovery in Sri Lanka
}

\author{
Dr P M Fernando* \\ Consultant in Anaesthetics and Critical Care \\ Luton and Dunstable University Hospital, United Kingdom.
}

*Corresponding author: pmfdo@hotmail.com

\begin{abstract}
The concept of 'Enhanced Recovery' is changing the face of surgical care pathways in western countries, benefiting patients as well as healthcare providers. The improvement in outcomes claimed would be of even greater benefit to developing countries, where resources are harder to come by. However, implementation of such a program in a developing country such as Sri Lanka needs to be preceded by thorough study of the obstacles to early discharge of patients, and the program customised to address problems specific to the local healthcare environment.
\end{abstract}

Keywords: enhanced recovery; peri-operative medicine; developing countries; healthcare improvement

'Enhanced Recovery' is about reducing length of hospital stay for patients using a care package based on scientific evidence. The concept originated in a peri-operative care setting, but is fast spreading to the management of medical patients as well. The 'end products' of an Enhanced Recovery program should include a better patient experience, fewer number of days spent as an in-patient (no more over-crowded wards), reduced post-operative complications, and reduction in cost per patient. In other words, everyone's a winner.

The current global economic climate, requiring service providers to provide 'more for less' has accelerated the interest in Enhanced Recovery where healthcare is provided as a service, or where care packages have a fixed price-tag. This has got the managers of healthcare institutions interested in this concept, which was born amidst clinicians working at the coal face.

\section{A bit about its history....}

As doctors we learnt the basics of medicine and surgery at medical school, and thereafter, we went our own ways - doing our best for patients within whatever speciality we chose. The surgeons liked to use generous incisions to provide good exposure, enabling them to do a good job fast. The anaesthetist took pride in the nerve block that worked well, and the pain relief modalities that kept the patient virtually pain free. We liked to give plenty of fluids for our patients to keep them well hydrated. Nurses and physiotherapists did their bit to the best of their ability. We all did our bit for the patient, and took comfort in the knowledge that we had done our best. However, I think it is true to say that we did not think much about the interplay of the interventions offered by the different specialities, and the net effect they had on the patient and the length of hospital stay.

Interest in enhanced recovery and the concept of 'peri-operative medicine' was born with the dawn of the new millennium. In the UK, perhaps the most important piece of work that gave momentum to the program came from the Improving Surgical Outcomes Group - that comprised of surgeons and anaesthetists who got together to look at ways of improving patient outcomes and increasing clinical efficiency. They produced two publications that are available online. ${ }^{1}$ The NHS Institute for Innovation and Improvement took on the task of expanding on the concept, and spreading interest within the NHS. ${ }^{2}$ The establishment of the Commissioning for Quality and Innovation (CQUIN) payment framework has added financial incentives that have resulted in hospital managements encouraging clinicians to adopt specific recommendations since 2009/10. ${ }^{3}$ Enhanced recovery has been alluded to during presentations at recent Annual Sessions of the College of Anaesthesiologists of Sri Lanka, and has been the subject of the editorial in the Sri Lankan Journal of Anaesthesiology. 


\section{Outcomes of the program}

The focus of the program in UK has been mainly on total hip replacements (THR), total knee replacements (TKR) and bowel resections. However, the principles are spreading rapidly to other surgical procedures as well. To give a flavour of what improvements can be expected, the average length of stay after a TKR can be reduced from 8 days to 5 days 5 and the average hospital stay after a large bowel resection can be reduced from 16 days to 8 days. ${ }^{6}$ All surgical units involved in this initiative have to ensure that early discharge is being made possible by faster recovery and not by premature discharge by recording re-admission rates.

If I were to pick the main contributors to the change, they would be:

1. Early pre-operative assessment, preparation, and planning of the level of post-operative care required.

2. Structured patient care pathways spellingout the expectations on day 1 , day 2 etc.

3. More patient involvement in his / her care.

4. Minimally invasive surgery, with no 'tubes or drains'.

5. Flow directed fluid optimisation - using minimally invasive cardiac output monitors.

6. Avoiding large doses of strong opioids, and multimodal analgesia targeting a pain score of $3 / 10$.

7. Early feeding and mobilisation.

\section{Applying the principles in Sri Lanka}

It has to be realised that the Enhanced Recovery Program was launched in the UK after thorough study of the surgical pathway in the UK, and comprehensive analysis of data related to patient outcomes and hospital stay. Although there are many lessons we can learn from the UK experience, trying to blindly apply the principles in Sri Lanka - where obstacles to reducing length of stay may be completely different - will only lead to a waste of resources at best, and potential harm to patients.

As men and women dedicated to science, we need to apply the scientific principles we learnt if we are to design an enhanced recovery program that is relevant and beneficial in a Sri Lankan setting.
First and foremost, there needs to be motivation and the willingness to change among healthcare providers. Making change within a large healthcare institution is a daunting, but achievable task. There are plenty of resources available for those interested. ${ }^{7}$ The key principle is to 'start small' - think of what you can do today within your practice, get those working closely with you interested.

Find your baseline. What is the average length of stay after a given surgical procedure? What makes some patients stay for much longer than others? No improvement can be demonstrated without knowing where you started. The value of having national data cannot be overemphasised. In the absence of national data, a retrospective / prospective audit of 100 consecutive patients should give a reasonable idea of your 'baseline'.

Study the current surgical care pathway. During a recent visit to an orthopaedic unit in Sri Lanka, I learnt that patients undergoing a total knee replacement are admitted a week before the date of operation, and kept in hospital at least until removal of sutures 2 weeks later. This would give a length of stay of over 21 days. A new patient would be admitted only when there is an empty bed - whenever that may be. This pathway has obviously evolved over many years, and there were probably very good reasons. There was a time when the fastest means of contacting a patient would be a telegram! Times have changed, but have the surgical care pathways followed suit? I learnt that the current waiting time for a total knee replacement would be more than 2 years. Has anyone counted the human suffering involved for patients and carers and the associated loss of productivity?

Question whether the pathway can be changed, so that the length of stay in hospital is reduced. Can pre-operative investigations be done at an outpatient clinic - close to the patient's home? Can the removal of stitches take place at a local hospital / clinic after discharge? There are bound to be social and organisational issues that will need to be overcome, but haven't we overcome much greater challenges in the past? A hospital should not be used as a budget hotel. Low cost accommodation close to the hospital could be arranged in collaboration with other agencies if this is a key issue. 
Decide on what to change, and try this out within a small unit / ward as an experiment. If this is successful - spread the word. If it isn't (it's not a national disaster!) - find out why, and what else needs to be done. Share your findings with others, and learn from the experience of others.

There needs to be a continuous process of auditing and re-auditing the impact of any intervention. Surgical pathways need constant re-evaluation.

\section{So what has all this got to do with anaesthetics?}

Although many interventions within Enhanced Recovery are not directly related to anaesthetics, anaesthetists are a major driving force within the program as we are unique in having involvement across all major surgical specialities, preassessments, and post-operative care. We are also quite used to working as a team, and are gifted with inter-personal skills that are invaluable in driving change.

The time has come for anaesthetists to think way beyond the tracheal tube, and play a much wider and meaningful role in improving patient experience.

Good luck!

\section{References:}

1. http://www.reducinglengthofstay.org.uk/isog.ht $\mathrm{ml}$

2. http://www.institute.nhs.uk/quality and service improvement tools/quality and service improvement tools/length of stay.html

3. http://www.institute.nhs.uk/world class commissioning/pct portal/cquin.html

4. Sri Lankan Journal of Anaesthesiology Vol.19(2) 2011 pp.59-60

5. http://www.london.nhs.uk/webfiles/Enhanced Recovery 20 Presentations/July 202011/Heather 20Caudle 20- 20Orthopaedics 20workshop.pdf

6. http://www.improvement.nhs.uk/winning principles/principles $2 / 61008 \quad 13$ queenmarys sidcup.pdf

7. http://www.ihi.org/Pages/default.aspx 